\title{
Article \\ Portomesenteric Vein Thrombosis after Bariatric Surgery: An Online Survey
}

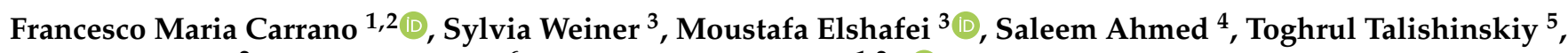 \\ Valeria Tognoni ${ }^{2}$, Kamal Mahawar ${ }^{6}$ and Nicola Di Lorenzo ${ }^{1,2, * \mathbb{D}}$ \\ 1 PhD Program in Applied Medical-Surgical Sciences, University of Rome “Tor Vergata”, 00133 Rome, Italy; \\ carranofm@gmail.com \\ 2 Department of Surgical Sciences, University of Rome "Tor Vergata", 00133 Rome, Italy; vtognoni@gmail.com \\ 3 Department of Metabolic Surgery, Krankenhaus Nordwest, Steinbacher Hohl 2-26, 60488 Frankfurt, Germany; \\ sylvia.weiner@gmx.de (S.W.); elshafei.moustafa@gmail.com (M.E.) \\ 4 Department of Upper Gastrointestinal and Bariatric and Metabolic Surgery, Tan Tock Seng Hospital, \\ Singapore 308433, Singapore; medicsaleem@gmail.com \\ 5 Hackensack University Medical Center, Hackensack, NJ 07601, USA; talishinskiy.toghrul@gmail.com \\ 6 Department of Surgery, Sunderland Royal Hospital, Sunderland SR4 7TP, UK; kmahawar@gmail.com \\ * Correspondence: Nicola.di.lorenzo@uniroma2.it
}

\section{check for} updates

Citation: Carrano, F.M.; Weiner, S.; Elshafei, M.; Ahmed, S.; Talishinskiy, T.; Tognoni, V.; Mahawar, K.; Di Lorenzo, N. Portomesenteric Vein Thrombosis after Bariatric Surgery: An Online Survey. J. Clin. Med. 2021, 10, 4024. https://doi.org/10.3390/ jcm10174024

Academic Editors: Andrea Mancuso, Giovanni Perricone, Xingshun Qi and Dominique Valla

Received: 24 July 2021

Accepted: 30 August 2021

Published: 6 September 2021

Publisher's Note: MDPI stays neutral with regard to jurisdictional claims in published maps and institutional affiliations.

Copyright: (c) 2021 by the authors. Licensee MDPI, Basel, Switzerland. This article is an open access article distributed under the terms and conditions of the Creative Commons Attribution (CC BY) license (https:/ / creativecommons.org/licenses/by/ $4.0 /)$.

\begin{abstract}
Portomesenteric vein thrombosis (PMVT) is a rare post-operative complication of bariatric procedures, occurring in between $0.3 \%$ and $1 \%$ of cases. A structured questionnaire consisting of 27 items was available online to members of the International Federation for the Surgery of Obesity and Metabolic Disorders (IFSO) to investigate the occurrence of PMVT. A total of 89 bariatric surgeons from 61 countries participated. Twenty-six (29.21\%) reported at least one case of PMVT (46.15\% males; $53.84 \%$ females). The surgery most associated with PMVT occurrence was sleeve gastrectomy (84.6\%), followed by Roux-en-Y gastric bypass (RYGB) (7.69\%), and laparoscopic adjustable gastric banding (LAGB) (7.69\%). The time gap between surgery and PMVT was $19.28 \pm 8.72$ days. The predominant symptom was abdominal pain in $96.15 \%$ of patients, followed by fever in $26.9 \%$. Complete occlusion of the portal vein was reported in $34.6 \%$ of cases, with involvement of the portal system in $69 \%$, extension to the superior mesenteric district in $23 \%$, and extension to the splenic vein in two patients (7.7\%). Our survey, which is the largest regarding PMVT to date, revealed a diffuse lack of standardization in the choice, duration, and dosing of prophylaxis regimens as well as treatment modalities, reflecting the literature gap on the topic.
\end{abstract}

Keywords: portomesenteric vein thrombosis; bariatric surgery; portal vein thrombosis; sleeve gastrectomy; RYGB

\section{Introduction}

Bariatric surgery (BS) is recognised as the most effective treatment for morbid obesity [1] and its associated co-morbidities [2]. The global volume of bariatric procedures has increased considerably over the last decade, reaching approximately 833,000 operations in 2019, of which 391,423 (47.0\%) were sleeve gastrectomy procedures (LSG), 294,530 (35.3\%) Roux-en-Y gastric bypass (RYGB) operations, 70,085 (8.4\%) gastric banding procedures, 30,914 (3.7\%) one-anastomosis gastric bypass procedures (OAGB), and 2744 more invasive biliopancreatic diversions/sleeve gastrectomies with duodenal switch (BPD/DS) that represent less than $1 \%$ of bariatric procedures [3]. Moreover, the field of bariatric surgery is constantly evolving towards less invasive endoscopic approaches [4].

Portomesenteric venous thrombosis (PMVT) refers to a partial or complete obstruction of the portal venous system in the intra- or extra-hepatic venous tract or affecting the splenic or superior mesenteric veins. Its consequences can be severe, and include ascites (62\%), esophageal varices $(58 \%)$, terminal gastroesophageal bleeding ( $47 \%)$, bowel infarction, and 
death [5]. The most common reported causes of PMVT are myeloproliferative disorders, deficiencies of anticoagulant proteins, prothrombotic gene mutations, cirrhosis with portal hypertension, and hepatocarcinoma [6].

Though many cases of PMVT have been reported in the scientific literature following $\mathrm{BS}$, its presentation, pathogenesis, diagnosis, and management remain unclear [7]. The aim of this survey was to understand the incidence, presenting symptoms, possible risk factors, diagnosis, treatment, and outcomes of PMVT.

\section{Materials and Methods}

A study group consisting of an international panel of surgeons with experience in bariatric surgery drafted a structured questionnaire that consisted of 27 items (Online Appendix A) divided into the following sections: (I) Participant experience; (II) Patient characteristics; (III) Coagulation state; (IV) Pharmacological anamnesis; (V) Surgical procedure; (VI) Pre-operative data; (VII) Intra-operative data; (VIII) Post-operative data; (IX) Portal vein thrombosis diagnosis; (X) Imaging studies; (XI) Thrombosis site; (XII) PMVT treatment; and (XIII) Outcome. The survey questions were close-ended. Consent of survey participants was obtained with a direct question in the survey. If participants had at least one case of PVT in their experience, they were required to respond to all questions for their responses to be registered, otherwise the survey was terminated. Patients were identified using surgeons' personal records.

\subsection{Sampling Plan and Invitation}

Members of the European Chapter of the International Federation for the Surgery of Obesity (IFSO-EC) were invited to participate in the survey through: (I) Email invitation to IFSO-EC members and affiliated individuals; or (II) The IFSO-EC email newsletter sent to IFSO members and affiliated individuals. Individual invitations were sent. Participants were informed that data was anonymised, confidential, and were provided a web link directing to the survey instrument. For the survey we used Google Forms, and it was hosted by Google LLC (Mountain View, CA, USA).

\subsection{Statistical Analysis}

A recorded summary of the results for each question was generated. Standard descriptive statistics were used.

\section{Results}

A total of 89 bariatric surgeons from 61 countries participated. Survey response rate was $4 \%$. Most participants were based in Europe $(91 \%) ; 65.16 \%(58)$ were practicing in high-volume bariatric centres ( $>100$ bariatric operations per year), while the remaining $34.84 \%$ (31) worked in hospitals with a medium- or low-volume of bariatric procedures.

Twenty-six $(29.21 \%)$ reported at least one case of PMVT in their clinical practice after bariatric surgery. Of those, only five (19.23\%) worked in low- or medium-volume institutions, while twenty-one surgeons $(80.76 \%)$ worked in high-volume bariatric centres.

The cases of PMVT submitted occurred in twelve males (46.15\%) and fourteen females (53.84\%). The median pre-operative body mass index (BMI) was $44.55 \pm 5.32 \mathrm{~kg} / \mathrm{m}^{2}$; the median pre-op weight was $129.26 \pm 20.79 \mathrm{~kg}$ (Table 1). Among the patients that received pre-operative study for altered coagulation states, three had a known coagulation disorder $(12 \%)$, two of them had protein $S$ deficiency, while one was reported as a nonspecific prothrombotic state. Three patients had a previous history of deep vein thrombosis and one of these had protein $\mathrm{S}$ deficiency. Four patients were under medication with selective serotonin reuptake inhibitors (SSRIs) $(16.6 \%)$. 
Table 1. Survey patient characteristics.

\begin{tabular}{cc}
\hline N Patients & 26 \\
Surgery & LSG 22/RYGB 2/LAGB 2 \\
Sex & $14 \mathrm{~F} / 12 \mathrm{M}$ \\
Median pre-op weight & $129.26 \pm 20.79 \mathrm{~kg}$ \\
Median BMI & $44.55 \pm 5.32 \mathrm{~kg} / \mathrm{m} 2$ \\
Coagulation disorder & $3(12 \%)$ \\
Previous DVT & $3(12 \%)$ \\
SSRIs & $4(16.6 \%)$ \\
\hline
\end{tabular}

BMI: Body Mass Index; DVT: Deep Vein Thrombosis; LAGB: Laparoscopic Adjustable Gastric Banding; LSG: Laparoscopic Sleeve Gastrectomy procedures; RYGB: Roux-en-Y Gastric Bypass.

The surgery most associated with PMVT occurrence in this survey was sleeve gastrectomy, with twenty-two out of twenty-six cases (84.6\%); two patients developed PMVT after RYGB $(7.69 \%)$ and two after LAGB $(7.69 \%)$, as shown in Figure 1.
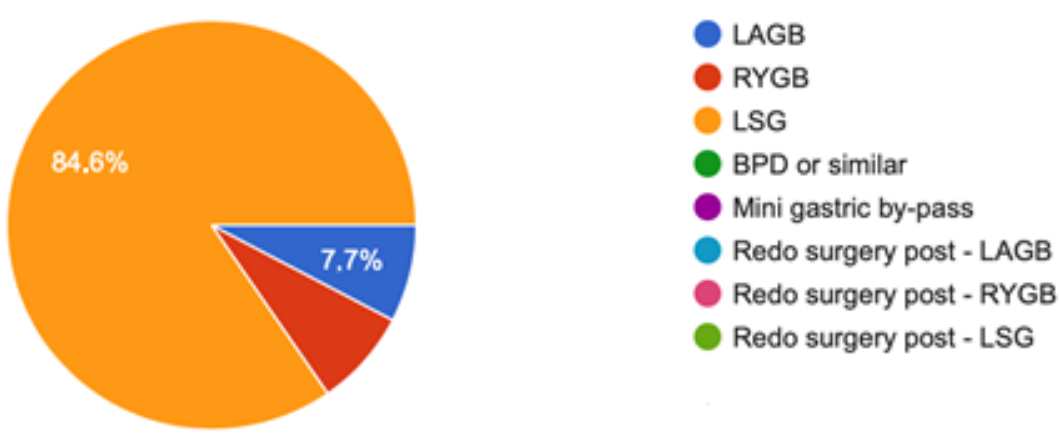

Figure 1. Procedures associated with PMVT. PMVT: Portomesenteric vein thrombosis; RYGB: Roux-enY gastric bypass; LSG: sleeve gastrectomy procedures; BPD: biliopancreatic diversions LAGB: Laparoscopic Adjustable Gastric Banding.

The median operative time reported was $64.76 \pm 27.6 \mathrm{~min}$ with no intraoperative complications.

The time gap between surgery and PMVT was $19.28 \pm 8.72$ days. Antithrombotic prophylaxis was administered to all these patients with low molecular weight heparin (LMWH) and/or compression stockings.

The predominant symptom (Table 2) was abdominal pain, seen in twenty-five out of twenty-six patients $(96.15 \%)$, followed by nausea and vomiting that were reported in twelve and seven cases respectively $(46.15 \%$ vs. $26.9 \%)$. Fever was present in seven patients $(26.9 \%)$. Five patients showed anorexia $(19.2 \%)$. Diarrhoea was present in three patients $(11.5 \%)$ and, in one case, intestinal bleeding $(3.8 \%)$ was the initial presentation.

Table 2. PMVT presenting symptoms.

\begin{tabular}{cc}
\hline Symptom & Patients (\%) \\
\hline Abdominal pain & $26(96.15 \%)$ \\
Fever & $7(26.9 \%)$ \\
Anorexia & $5(19.2 \%)$ \\
Nausea & $12(46.15 \%)$ \\
Vomit & $7(26.9 \%)$ \\
Diarrhoea & $3(11.5 \%)$ \\
Intestinal bleeding & $1(3.8 \%)$ \\
\hline
\end{tabular}

Diagnosis was achieved after a contrast-enhanced abdominal CT scan in all cases, alone or in combination with abdominal doppler ultrasound. In $34.6 \%$ of the patients, there was complete occlusion of the portal system (Figure 2). Figure 3 provides percentages for the extent of portal venous system involvement. 


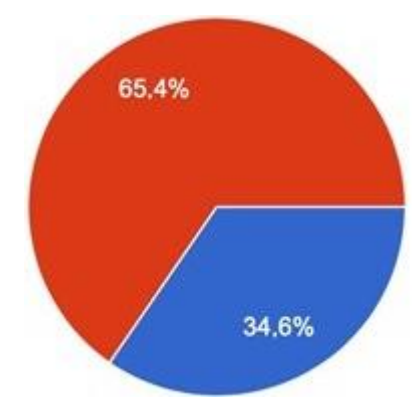

Complete occlusion (no residual flow visible)

Non occlusive (residual flow visible)

Figure 2. Grade of occlusion of the portal system.
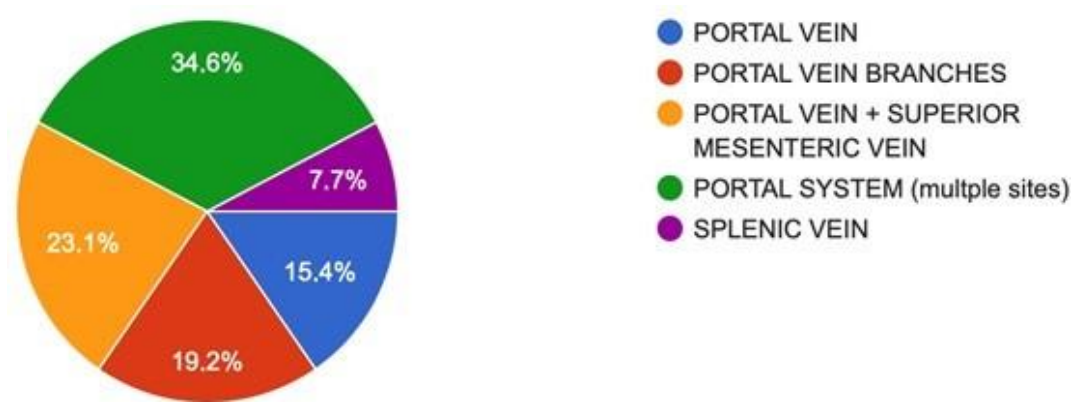

Figure 3. Extent of portal system involvement.

All patients received medical treatment with one of the following: unfractionated heparin, LMWH or oral anticoagulant. Endovascular thrombolysis was performed in one patient (3.8\%). Two patients required a diagnostic laparoscopy $(7.7 \%)$, but no bowel resection was required, and no deaths occurred. All patients were treated successfully and achieved complete resolution of the thrombosis.

\section{Discussion}

Portomesenteric vein thrombosis is a known complication after bariatric surgery. In our survey, only $29.21 \%$ of responders reported at least one case of PMVT in their practice, most of them coming from high-volume bariatric centres, with no significant differences in gender. Although rare, its incidence has been increasing on par with the number of bariatric procedures performed worldwide, occurring in $0.3-0.4 \%$ of cases, mostly after LSG $(78.9 \%)$ and RYGB $(13.8 \%)[7,8]$. Our survey reflects the data in the literature, with LSG being the procedure most associated with PMVT, followed by RYGB and LAGB.

PMVT usually begins with a mild presentation that can be managed conservatively. However, in severe cases, it can potentially be lethal due to the risk of associated bowel ischemia (Figure 4 ) and potential late risk of chronic bilioportal cholangiopathy that can lead to small bowel resection and even liver transplantation [9]. Moreover, the occurrence of PMVT is among the factors that influence early postoperative liver function capacity of patients after bariatric surgery [10].

In our survey, the most common presentation was abdominal pain in over $96 \%$ of cases, followed by nausea in almost half of cases, and vomiting in $27 \%$. Less than $30 \%$ of patients had a fever. Less frequent initial presentations included anorexia, diarrhoea, and intestinal bleeding. Similar findings are reported in a systematic review by Shoar S. et al., in which the most common presentations of PMVT were abdominal pain (82.7\%), nausea/vomiting $(38.2 \%)$, leukocytosis $(20 \%)$, and fever $(12.7 \%)$. Other less common presenting symptoms were tachycardia $(10.9 \%)$, increased liver function tests $(11.8 \%)$, elevated erythrocyte sedimentation rate/C-reactive protein level $(10 \%)$, and malabsorption $(9.1 \%)$. 

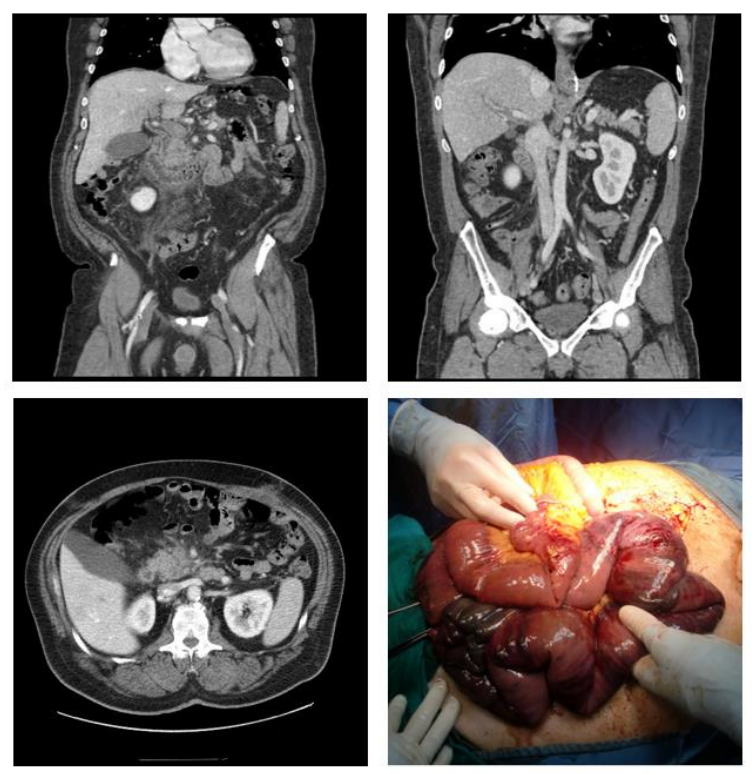

Figure 4. Case of portal vein thrombosis after biliopancreatic diversion; CT scan showing extended PVT associated with bowel ischemia, and related intraoperative findings. PVT: Portal Vein Thrombosis.

Although the only predominant symptom in our series was abdominal pain, the early recognition of PMVT with the use of abdominal ultrasound and contrast-enhanced CT scans was important to provide early conservative treatment. All patients received medical treatment with either unfractionated heparin, $\mathrm{LMWH}$, or oral anticoagulant. Only one patient required endovascular thrombolysis, while two underwent a diagnostic laparoscopy without the need for any bowel resection. Similar treatment strategies are reported in the literature, with interventional radiology techniques allowing relatively easy treatment of portal thrombosis in non-cirrhotic patients [5,11].

No clear predisposing factor or causative agent emerged from our survey. Among the patients that received specific pre-operative coagulation study, $12 \%$ had a known coagulation alteration, and $11.5 \%$ had a previous history of deep vein thrombosis. The use of SSRIs was reported in $16.6 \%$ of patients with PMVT, although no conclusions can be drawn on any causative relationship between SSRIs and PMVT due to the low number of cases. Several causes have been suggested in the past, although none have been identified as solely responsible. A status of hypercoagulopathy is retrieved in less than half of patients, with several different coagulation factors implicated in its genesis; thus, the possible cause remains unknown in the majority of cases. Recently, a case of PMVT after RYGB has been reported in a young patient with a SARS-CoV-2 viral infection [12], which is known to lead to a hypercoagulopathic state that can result in PMVT [13] and mesenteric ischemia [14]. Previously, other viral infections have been reported in PMVT, including Epstein-Barr and cytomegalovirus, as well as in healthy and immunocompetent patients [15]. The role of viral infections in the genesis of PMVT after bariatric surgery has not been investigated yet. Several different mechanisms have been held responsible for cases of PMVT occurring after LSG, including rearrangement of the splanchnic venous flow secondary to ligation of the short gastric vessels [16], oedema of the sleeve causing venous obstruction or dehydration, or compression of venous flow by liver retraction [8]. Although the reduction of portal venous flow is a known factor for the occurrence of PMVT [17], it is yet to be clarified if transitory flow reduction during surgery can be sufficient to initiate PMVT. A recent study by Osman et al. associated LSG with greater reduction in portal venous peak systolic flow velocity in the early postoperative period, compared to other bariatric procedures, although no PMVT occurred in the study cohort [18]. Induction of a pneumoperitoneum with an intra-abdominal pressure of more than $14 \mathrm{mmHg}$ has been demonstrated to reduce portal venous blood flow by $50 \%$, that is further reduced 
by the prolonged reverse-Trendelenburg position. A hypercapnic state may also cause mesenteric vasospasm that eventually reduces venous blood flow, increasing the risk of blood clot formation. However, these factors exist for many other laparoscopic procedures that are not associated with an increased risk of PMVT [19] and can hardly explain the mean occurrence of PMVT 19 days after surgery. Some authors also hypothesise a role of high energy ultrasonic devices that may favor thrombus formation and dissemination through the portal venous system due to the mechanical and thermal energy transmitted to blood vessels and surrounding tissues [20,21], although there is no strong evidence currently supporting this theory, as no dedicated studies have investigated this particular aspect and PMVT cases are reported when only bipolar energy devices were used. In our survey, no particular risk factor was predominantly associated with PMVT.

We believe that the analysis of the data collected with the survey can offer a general and more realistic overview of the occurrence of PMVT in the bariatric population compared with studies available in the literature-most of them retrospective and on small cohorts of patients. An interesting finding of our study is that the time between surgery to PMVT presentation was $19.28 \pm 8.72$ days. This data suggests that a short course antithrombotic prophylaxis of less than 15 days may not be sufficient to lower the risks of such a complication. Moreover, this is consistent with the experience of Manish et al. on the systematic use of extended chemoprophylaxis, that decreased the rate of PMVT from $0.3 \%$ to $0.1 \%$ without a significant increase in the number of bleeding episodes [8]. A clear fact emerging from this survey is the great heterogeneity not just in choice but also in the duration and dosing of antithrombotic prophylaxis. It is also worth considering that currently available calculators used to predict the risk of VTE do not take into consideration PMVT, reflecting a further lack of tools to standardise the approach on the prevention of PMVT and VTE in general.

One limitation of our study is the low response rate to the questionnaire. We think that this might be due to the rarity of the condition so that most surgeons, and even bariatric surgeons, would not have encountered it in their practice. The diverse results collected by our survey are also representative of the lack of quality evidence regarding PMVT, as most of the studies have different inclusion criteria, do not follow a standardised surgical technique (rendering comparison difficult), adopt different types of thrombophylactic regimens, as well as different diagnostic and treatment algorithms. For this reason, prospective studies with sufficient power should be encouraged to fill this important gap in the literature.

\section{Conclusions}

PMVT is a rare complication in bariatric surgery, however, it can have severe consequences. Early detection through cross-sectional imaging is fundamental for positive treatment results. Our survey that represents the largest survey on PMVT to date, revealed a diffuse lack of standardization in the choice, duration, and dosing of prophylaxis regimens as well as treatment modalities, reflecting the literature gap on the topic. Further studies should be encouraged to address this important issue.

Author Contributions: Conceptualization, F.M.C. and N.D.L.; methodology, F.M.C. and N.D.L.; formal analysis, F.M.C.; data curation, F.M.C. and V.T.; writing-original draft preparation, F.M.C., V.T. and N.D.L.; writing-review and editing, F.M.C., S.W., M.E., S.A., T.T., V.T., K.M. and N.D.L.; visualization, F.M.C.; supervision, N.D.L., K.M., All authors have read and agreed to the published version of the manuscript.

Funding: This research received no external funding.

Informed Consent Statement: Written informed consent has been obtained from the participants of the survey to publish the results.

Data Availability Statement: The data presented in this study are available on request from the corresponding author. The data are not publicly available due to privacy restrictions. 
Acknowledgments: We would like to thank all our colleagues who generously participated in the survey.

Conflicts of Interest: The authors declare no conflict of interest.

\section{Appendix A}

\section{PORTAL VEIN THROMBOSIS IN BARIATRIC SURGERY \\ SURVEY \\ * Required}

1. How many bariatric surgical operations do you perform at your Institution per year?

Mark only one oval.

Less than 50

Between 50 and 100

More than 100

2. Have you ever faced portal vein thrombosis in your Bariatric Surgery Unit? *

Mark only one oval.

Yes

$\bigcirc$ No

PORTAL VEIN THROMBOSIS

Please report the following data for each case of portal vein REPORT SHEET

thrombosis after bariatric surgery

3. SEX *

Mark only one oval.

Male

Female

Figure A1. Cont. 


\section{PRE-OPERATIVE WEIGHT (Kilograms) *}

5. $\mathrm{BMI}(\mathrm{Kg} / \mathrm{m} 2)$ *

\section{COAGULATION STATE}

\section{COAGULATION ALTERATIONS *}

Mark only one oval per row.

\begin{tabular}{|c|c|c|c|}
\hline & YES & NO & $\mathrm{N} / \mathrm{A}$ \\
\hline Prothrombotic state & & & \\
\hline Hereditary thrombophilia & & & \\
\hline Antithrombin III deficiency & & & \\
\hline Protein $\mathrm{C}$ deficiency & & & \\
\hline Protein S deficiency & & & \\
\hline Factor V Leiden mutation & & & \\
\hline Prothrombin G20210A mutation & & & \\
\hline Hyperhomocysteinemia & & & \\
\hline Previous DVT episodes & & & \\
\hline Anti-cardiolipin antibodies & & & \\
\hline $\begin{array}{l}\text { Plasminogen Activator Inhibitor - } 1 \text { (PAI-1) } \\
\text { polymorphism }\end{array}$ & & & \\
\hline
\end{tabular}

PHARMACOLOGICAL ANAMNESIS

Figure A1. Cont. 
7. Which of the following drugs were taken, at the time of the operation or in the past, by the patient? *

Mark only one oval per row.

\begin{tabular}{lll}
\hline Oral contraceptive & YES \\
Cox-2 inhibitors &
\end{tabular}

SSRI (es. Sertraline, Paroxetine, Fluoxetine, Citalopram, ecc.)

Antipsychotics (es. Clozapine, Quetiapine, Haloperidol, Clorpromazine, ecc.)

Tricyclic antidepressants (es. Amitriptiline, Imipramine, Nortriptiline, ecc.)

MAO inhibitors (es. Selegiline, Tranylcypromine, ecc.)

\section{SURGICAL PROCEDURE}

Figure A1. Cont. 
8. Select the performed procedure *

Mark only one oval.

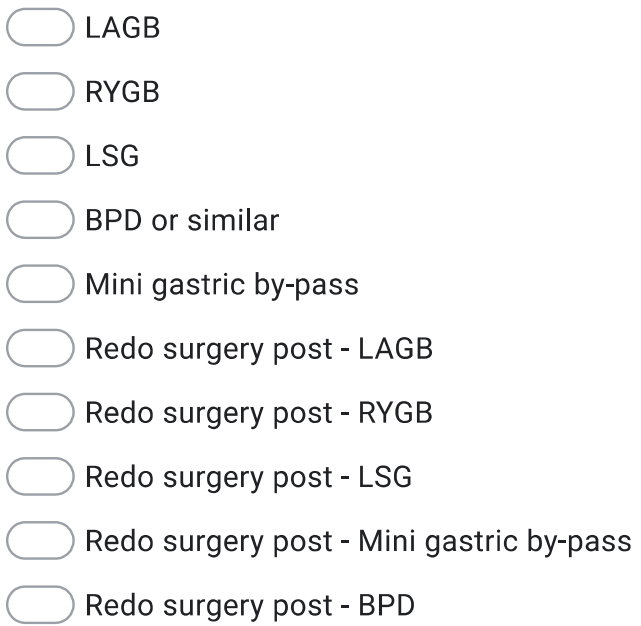

9. Pre-operative coagulation tests performed *

Check all that apply.

None

Prothrombin time (PT)

Activated partial thromboplastin time (APTT)

International Normalized Ratio (INR)

Platelet count

$\square$ Selective coagulation factor testing (i.e. fibrinogen, FII, FIII, FV, FVII, FVIII, FX, other)

Figure A1. Cont. 
10. If selective coagulation factor testing was performed, select all the abnormal values that apply

Check all that apply.

$\square$ Factor VIII

$\square$ PAl-1

$\square$ Fibrinogen

$\square$ Protein S

$\square$ Protein C

Other:

11. Which of the following apply *

Mark only one oval per row.

Antithrombotic prophylaxis
Compression stockings
Heparin

\section{INTRA-OPERATIVE DATA}

12. OPERATIVE TIME (Minutes) *

13. Intra-operative complications *

Mark only one oval.
YES
No

Figure A1. Cont. 
POST-OPERATIVE DATA

14. Time to Portal Vein Thrombosis occurrence (days) *

15. List any other complication

16. Which of the following apply during post-operative course *

Mark only one oval per row.

Antithrombotic prophylaxis
Compression stockings
Heparin

17. Duration of antithrombotic prophylaxis (if administered) * Mark only one oval.

3-10 days after surgery

11 - 30 days after surgery

More than 30 days after surgery

PORTAL VEIN THROMBOSIS DIAGNOSIS

Figure A1. Cont. 
18. At the moment of the diagnosis, which of the following options applies * Mark only one oval per row.

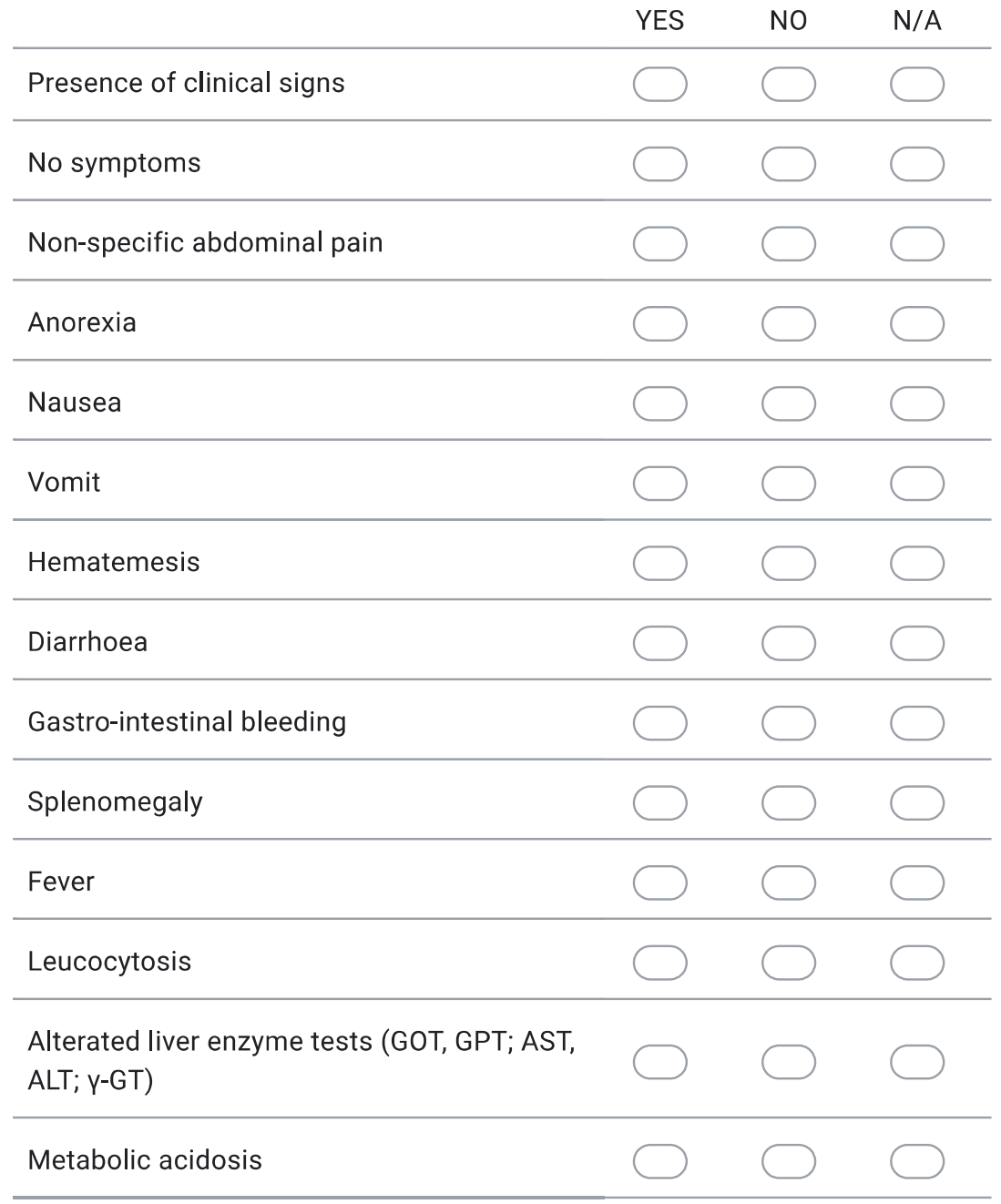

\section{IMAGING STUDIES}

Figure A1. Cont. 
19. Which of the following imaging studies were used to achieve the diagnosis? * Mark only one oval per row.

Ultrasound

20. Degree of portal venous system occlusion * Mark only one oval.

$\Longrightarrow$ Complete occlusion (no residual flow visible)

Non occlusive (residual flow visible)

\section{THROMBOSIS SITE}

21. Select the site of thrombosis *

Mark only one oval.

PORTAL VEIN

PORTAL VEIN BRANCHES

PORTAL VEIN + SUPERIOR MESENTERIC VEIN

$\longrightarrow$ PORTAL SYSTEM (multple sites)

SPLENIC VEIN

PVT TREATMENT

Figure A1. Cont. 
22. How was the patient treated? *

Mark only one oval.

ONLY WITH MEDICAL THERAPY (i.e. LMWH, Oral Vit. K antagonist)

MEDICAL + ENDOVASCULAR THROMBOLYSIS

MEDICAL + PERCUTANEOUS THROMBECTOMY

$\bigcirc$ LAPAROTOMY or EXPLORATORY LAPAROSCOPY

\section{OUTCOME}

23. Final outcome *

Mark only one oval.

Resolution

$\longrightarrow$ DEATH

Privacy and data protection

24. What is your Institution? *

25. Do you authorize any eventual processing of this data for scientific research purposes only? *

Mark only one oval.

YES

$\bigcirc$ No

Figure A1. Cont. 
26. Do you authorize the authors of this survey to contact you via email exclusively for scientific research purposes? *

Mark only one oval.

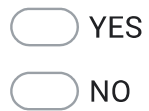

27. If you have granted previous authorization, please provide your contact information. Thanks a lot for your cooperation!

This content is neither created nor endorsed by Google.

\section{Google Forms}

Figure A1. Portal vein thrombosis in bariatric surgery. 


\section{References}

1. Welbourn, R.; Pournaras, D.J.; Dixon, J.; Higa, K.; Kinsman, R.; Ottosson, J.; Ramos, A.; van Wagensveld, B.; Walton, P.; Weiner, R.; et al. Bariatric Surgery Worldwide: Baseline Demographic Description and One-Year Outcomes from the Second IFSO Global Registry Report 2013-2015. Obes. Surg. 2018, 28, 313-322. [CrossRef]

2. Phillips, B.T.; Shikora, S.A. The history of metabolic and bariatric surgery: Development of standards for patient safety and efficacy. Metabolism 2018, 79, 97-107. [CrossRef]

3. Ramos, A.; Kow, L.; Brown, W.; Welbourn, R.; Dixon, J.; Kinsman, R.; Walton, P. Fifth IFSO Global Registry Report-2019. Obes. Surg. 2019, 29, 782-793.

4. Sangiorgi, G.M.; Cereda, A.; Porchetta, N.; Benedetto, D.; Matteucci, A.; Bonanni, M.; Chiricolo, G.; De Lorenzo, A. Endovascular Bariatric Surgery as Novel Minimally Invasive Technique for Weight Management in the Morbidly Obese: Review of the Literature. Nutrients 2021, 13, 2541. [CrossRef]

5. Tan, S.B.M.; Greenslade, J.; Martin, D.; Talbot, M.; Loi, K.; Hopkins, G. Portomesenteric vein thrombosis in sleeve gastrectomy: A 10-year review. Surg. Obes. Relat. Dis. 2018, 14, 271-275. [CrossRef]

6. Minoda, A.M.; Cadete, R.B.F.; Teixeira, S.R.; Muglia, V.F.; Elias Junior, J.; de Melo-Leite, A.F. The ABCD of portal vein thrombosis: A systematic approach. Radiol. Bras. 2020, 53, 424-429. [CrossRef]

7. Karaman, K.; Aziret, M.; Bal, A.; Öter, V.; Ercan, M.; Bostanc1, E.B. Porto-mesenteric venous thrombosis after laparoscopic sleeve gastrectomy: A case report and systematic review of the 104 cases. Obes. Res. Clin. Pract. 2018, 12, 317-325. [CrossRef]

8. Parikh, M.; Somoza, E.; Chopra, A.; Friedman, D.; Chui, P.; Park, J.; Ude-Welcome, A.; Saunders, J.K. Thrombophilia prevalence in patients seeking laparoscopic sleeve gastrectomy: Extended chemoprophylaxis may decrease portal vein thrombosis rate. Surg. Obes. Relat. Dis. 2020, 16, 839-843. [CrossRef]

9. Danion, J.; Genser, L.; Scatton, O. Sleeve Gastrectomy: You Might Lose your Liver! Obes. Surg. 2019, 29, 350-352. [CrossRef]

10. Schmitz, S.M.T.; Kroh, A.; Koch, A.; Brozat, J.F.; Stier, C.; Neumann, U.P.; Ulmer, T.F.; Alizai, P.H. Comparison of Liver Recovery After Sleeve Gastrectomy and Roux-en-Y-Gastric Bypass. Obes. Surg. 2021, 31, 3218-3226. [CrossRef]

11. Shoar, S.; Saber, A.A.; Rubenstein, R.; Safari, S.; Brethauer, S.A.; Al-Thani, H.; Asarian, A.P.; Aminian, A. Portomesentric and splenic vein thrombosis (PMSVT) after bariatric surgery: A systematic review of 110 patients. Surg. Obes. Relat. Dis. 2018, 14, 47-59. [CrossRef] [PubMed]

12. Goodfellow, M.; Courtney, M.; Upadhyay, Y.; Marsh, R.; Mahawar, K. Mesenteric Venous Thrombosis Due to Coronavirus in a Post Roux-en-Y Gastric Bypass Patient: A Case Report. Obes. Surg. 2021, 31, 2308-2310. [CrossRef] [PubMed]

13. Ofosu, A.; Ramai, D.; Novikov, A.; Sushma, V. Portal Vein Thrombosis in a Patient with COVID-19. Am. J. Gastroenterol. 2020, 115, 1545-1546. [CrossRef] [PubMed]

14. Parry, A.H.; Wani, A.H.; Yaseen, M. Acute Mesenteric Ischemia in Severe Coronavirus-19 (COVID-19): Possible Mechanisms and Diagnostic Pathway. Acad. Radiol. 2020, 27, 1190. [CrossRef]

15. Burkey, C.; Teng, C.; Hussein, K.I.; Sabetta, J. Cytomegalovirus (CMV)-associated portal vein thrombosis in a healthy, immunocompetent man. BMJ Case Rep. 2020, 13, e238645. [CrossRef]

16. Goitein, D.; Matter, I.; Raziel, A.; Keidar, A.; Hazzan, D.; Rimon, U.; Sakran, N. Portomesenteric thrombosis following laparoscopic bariatric surgery: Incidence, patterns of clinical presentation, and etiology in a bariatric patient population. JAMA Surg. 2013, 148, 340-346. [CrossRef]

17. Chawla, Y.K.; Bodh, V. Portal vein thrombosis. J. Clin. Exp. Hepatol. 2015, 5, 22-40. [CrossRef]

18. Osman, A.M.A.; Helmy, A.S.; Mikhail, S.; AlAyat, A.A.; Serour, D.K.; Ibrahim, M.Y. Early Effects of Laparoscopic Sleeve Gastrectomy and Laparoscopic One-Anastomosis Gastric Bypass on Portal Venous Flow: A Prospective Cohort Study. Obes. Surg. 2021, 31, 2410-2418. [CrossRef]

19. Godoroja, D.; Hainarosie, D.; Zaharencu, A.; Copaescu, C. Portal Vein Thrombosis a Rare but Life-threatening Complication after Laparoscopic Sleeve Gastrectomy: A 5 Years Study in a Bariatric Center of Excellence. Chirurgia 2019, 114, 711-724. [CrossRef] [PubMed]

20. James, A.W.; Rabl, C.; Westphalen, A.C.; Fogarty, P.F.; Posselt, A.M.; Campos, G.M. Portomesenteric venous thrombosis after laparoscopic surgery: A systematic literature review. Arch. Surg. 2009, 144, 520-526. [CrossRef]

21. Bani Hani, M.N.; Al Manasra, A.R.A.; Obeidat, F.; Al-Omari, M.H.; Bani Hani, F. Portomesenteric Venous Thrombosis PostLaparoscopic Sleeve Gastrectomy: Do Energy Systems Pose as Instigating Factor to This Infrequent Complication? Clin. Med. Insights Case Rep. 2019, 12. [CrossRef] [PubMed] 